\title{
Tizón por Phytophthora sojae en cultivos de soja de la provincia del Chaco (Argentina)
}

\author{
María Graciela Cabrera ${ }^{1}$, Susana Alejandra Gutiérrez ${ }^{1}$ y María Agueda Cúndom ${ }^{1}$
}

${ }^{1}$ Cátedra de Fitopatología, Facultad de Ciencias Agrarias, Universidad Nacional del Nordeste, Sargento Cabral 2131 CP 3400 , Corrientes, Argentina.Email: sualejandra@hotmail.com

Autor para correspondência: Susana Alejandra Gutiérrez sualejandra@hotmail.com

Data de chegada: 26/08/2007. Aceito para publicação em: 28/07/2008

El cultivo de soja, Glycine max (L.) Merr, es actualmente el más importante de Argentina ya que ocupa una amplia zona ecológica que va desde $\operatorname{los} 23^{\circ}$ en el extremo Norte del país a los $39^{\circ}$ de latitud sur. En los últimos años se observaron incrementos significativos respecto a la superficie sembrada en la región noreste y noroeste del país. Entre las limitantes que afectan al cultivo en Argentina, deben mencionarse las enfermedades cuya prevalencia e intensidad se incrementan considerablemente cada año (Cabrera et al. Hongos menores detectados en follaje de soja en Chaco y Corrientes, Argentina. 2006. Disponible en http://www.unne.edu.ar/Web/cyt/ cyt2006/index.htm).

Durante la campaña 2005/2006, en cultivos de soja implantados en la localidad de General San Martín de la provincia del Chaco (Argentina), se observaron plantas de soja, variedad Monsoy 8080 en estado R5, que presentaban síntomas de atizonamiento y podredumbre húmeda en hojas, pecíolos y tallos. La enfermedad se presentó con un $35 \%$ de incidencia en el lote afectado. Las lesiones se localizaban preferentemente cerca de los nudos medios y superiores de las plantas. El follaje circundante también manifestaba descomposición húmeda de sus tejidos, con posterior amarillamiento y muerte. Ante la presencia de éstos síntomas no observados anteriormente en la región, se realizó su estudio a fin de determinar la etiología de la enfermedad.

Se analizaron 15 plantas de soja enfermas, mediante la realización de cámaras húmedas con segmentos de tejidos enfermos (hojas, pecíolos y tallos); el microorganismo fue aislado a partir de trocitos de tejidos sintomáticos sembrados en

medio agarizado (Agar papa glucosado, 1,5\%, pH 6). Las características culturales y morfométricas del microorganismo aislado in vitro fueron analizadas en Agar poroto 2\%, y Agar V8, ambos a $\mathrm{pH}$ 6, en condiciones de $12 \mathrm{~h}$ luz, $12 \mathrm{~h}$ oscuridad y en medio líquido (Agua destilada estéril, en tubo de ensayo, $5 \mathrm{ml}$ ) (Frezzi, M.J. Las especies de Phytophthora en la Argentina. Revista de Investigaciones Agrícolas, t.4, n.1, p. 47-134, 1950)

La patogenicidad del agente causal, se probó en seis plantas sanas de soja de la misma variedad, criadas en macetas en invernáculo, depositando discos de inóculo (4-5) sobre la superficie de tallos y hojas sin heridas y con heridas. Se llevaron los testigos correspondientes (seis); las plantas inoculadas se cubrieron con bolsas de polietileno durante 48 horas, en condiciones de laboratorio $\left(25-26^{\circ} \mathrm{C}\right)$.

Los síntomas descritos en las plantas analizadas en condiciones de campo, no coincidieron con lo observado en cultivos de soja enfermos de otras regiones de la Argentina, ya que la podredumbre presente en el material de estudio, no afectaba la base del tallo ni las raíces de dichas plantas (Distéfano de Vallone, S.; Giorda, L. Editores Enfermedades de la soja en la Argentina. INTA Centro Regional Córdoba, 1997. 72 p.); los síntomas principalmente se detectaron en el tercio superior, situación que fue atribuida al riego por aspersión que se empleó en el cultivo afectado, favoreciendo a la aparición de la enfermedad.

Las pruebas de patogenicidad realizadas, fueron positivas a las 72 horas; todas las plantas inoculadas manifestaron síntomas similares a aquellos observados en el material de campo (Fig. 1).

El agente causal fue identificado como Phytophthora sojae Kaufmann y Gerdemann (Erwin, D.C. et al. Phytophthora Its Biology, Taxonomy, Ecology, and Pahtology 2.ed, St. Paul: The American Phytopathological Society, 1987. 392 p.; Erwin, D.C.; Ribeiro, O.K.

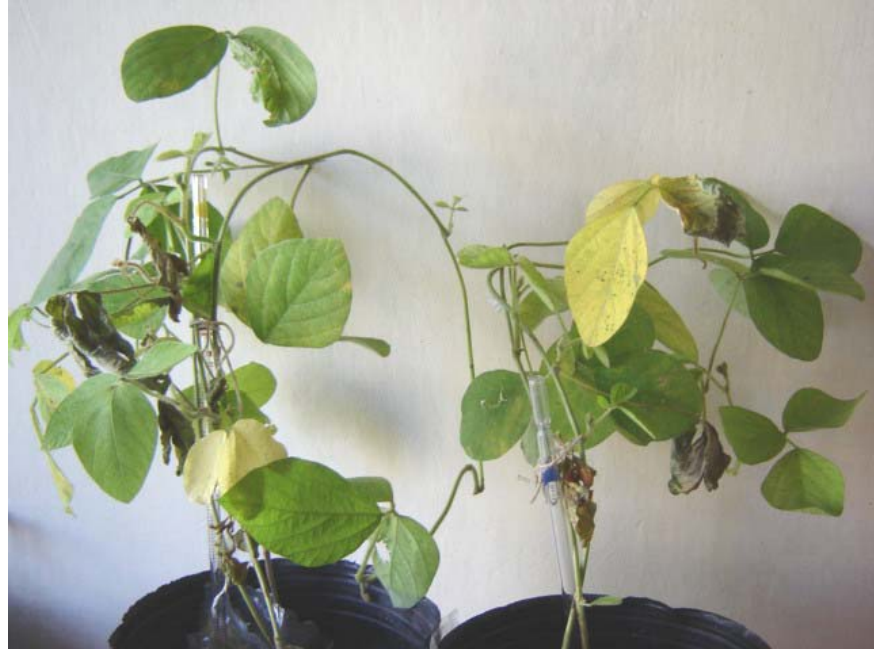

Figura 1. Sintomas en plantas de soja inoculadas con Phytophthora sojae.

Phytophthora Diseases Worldwide St. Paul: The American Phytopathological Society, 1996. 555 p.)

En los medios agarizados y líquido, el hongo desarrolló abundante micelio hialino, no tabicado, irregular con hinchazones y retorcimientos, no produciendo estructuras de reproducción asexual pero si abundante presencia de oosporas, de $27.5 \mu-37.5 \mu$ (promedio de 100 mediciones), con anteridios mayormente paráginos y clamidosporas (Fig. 2). Los aislamientos de P. sojae obtenidos, fueron depositados en la colección de hongos del Laboratorio de Fitopatologia, Facultad de Ciencias Agrarias, Universidad Nacional del Nordeste y son conservados en agua estéril, en heladera a $7^{\circ} \mathrm{C}$.

Constituye ésta es la primera información de la enfermedad causada por Phytophthora sojae en cultivos de soja de la provincia del Chaco, Argentina.

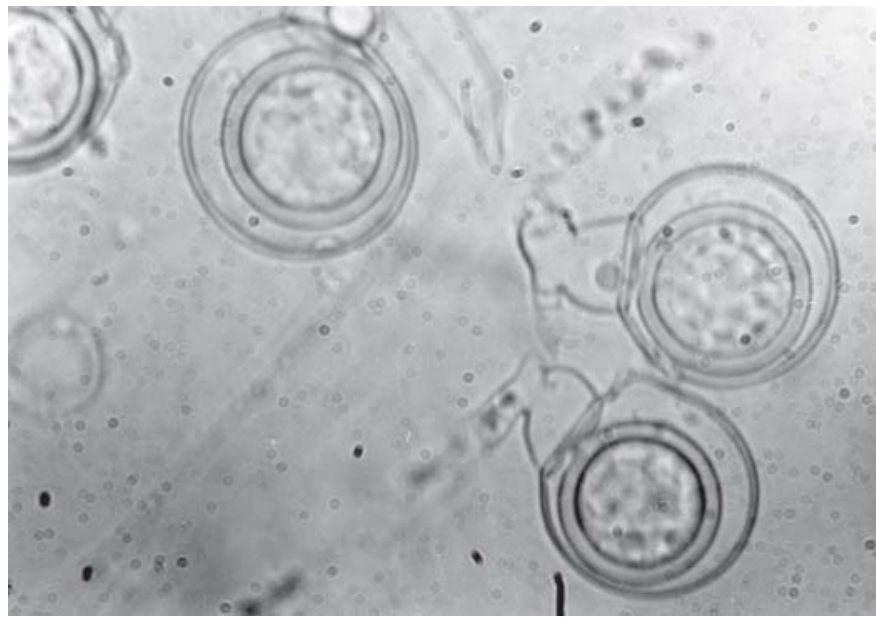

Figura 2. Oosporas de Phytophthora sojae 